\title{
Trochanteric fractures in the elderly: the influence of primary hip arthroplasty on 1-year mortality
}

\author{
Florian Geiger • Monique Zimmermann-Stenzel • \\ Christian Heisel · Burkhard Lehner · Wolfgang Daecke
}

Received: 21 December 2006 / Published online: 25 September 2007

(C) Springer-Verlag 2007

\begin{abstract}
Introduction The aim of the study was to compare the mortality risk and complication rate after operative treatment of pertrochanteric fractures with primary arthroplasty, dynamic hip screw (DHS) or proximal femoral nail (PFN). Patients and methods Clinical records including X-rays of all patients with trochanteric femoral fractures, except pathologic fractures and a minimum age of 60 years, which were treated between 1992 and 2005 were entered in this retrospective study. Of these 283 patients, 132 were treated by primary arthroplasty, 109 with a DHS and 42 with a PFN. Survival after 1 year and complications, which had to be treated within this period were our main outcome measurement. Influencing cofactors such as age, gender and comorbidities were reduced by multivariate logistic regression analysis.

Results Mortality was significantly influenced by age, gender and amount of comorbidities but not by fracture
\end{abstract}

F. Geiger · M. Zimmermann-Stenzel · C. Heisel ·

B. Lehner · W. Daecke

Orthopaedic University Hospital,

Schlierbacher Landstr. 200a, 69118 Heidelberg, Germany

e-mail: monique.zimmermann-stenzel@ ok.uni-heidelberg.de

C. Heisel

e-mail: christian.heisel@ok.uni-hd.de

B. Lehner

e-mail: burkhard.lehner@ok.uni-hd.de

W. Daecke

e-mail: w.daecke@friedrichsheim.de

F. Geiger $(\bowtie) \cdot$ W. Daecke

Orthopaedic University Hospital,

Stiftung Friedrichsheim, Marienburgstrasse 2,

60528 Frankfurt am Main, Germany

e-mail: f.geiger@friedrichsheim.de classification. Primary hip arthroplasty did not bear a higher 1-year mortality risk than osteosynthesis in a multiple regression analysis. The main complication with DHS and PFN were cutting out of the hip screw and non-union with a revision rate of $12.8 \%$. With the introduction of hemiarthroplasty, the postoperative dislocation rate decreased from 12 to $0 \%$.

Conclusion For stable fractures a dynamic hip screw (DHS) and for unstable fractures a short proximal femoral nail (PFN) can be recommended. The mortality risk of primary cemented arthroplasty did not differ significantly from the other treatment groups and because of its low complication rate it is a viable treatment option for trochanteric fractures if osteoporosis prevents from full weight bearing or if osteoarthritis makes further operations likely. Primary total hip replacement should be handled with care due to its significantly higher dislocation rate compared with hemiarthroplasty especially in unstable fractures.

Keywords Mortality risk - Trochanteric femoral fractures . Total hip replacement

\section{Introduction}

While relative consensus exists about the treatment of femoral neck fractures for elderly patients, the optimal treatment for per- and intertrochanteric fractures is still under debate $[1,7]$. In a previous study of 1,173 patients with proximal femoral fractures it appeared that trochanteric fractures are still a challenge, as 1-year mortality risk and complication rate were considerably higher compared with femoral neck fractures [7]. As restoration of the preoperative ambulatory level correlated with survival rate after 1 year [7] and elderly patients are often unable to cooperate 
with partial weight bearing, the primary stability of the device is crucial to allow early mobilization to prevent cardio-pulmonal complications and thrombosis. Excessive collapse of the fracture site and varus displacement is a common problem of sliding hip screws combined with plates or femoral nails especially in elderly women who often suffer from osteoporosis and poor bone quality [16]. Therefore, primary arthroplasty was proposed by some authors $[4,10,28]$ but their patient collectives ranging from 37 to 54 were to small to allow general recommendations. Because we used hip arthroplasty even for trochanteric fractures for a long time as a standard procedure $[7,26]$, we are now able to report on our experiences in a large number of patients.

This study compares the mortality risks and 1-year postoperative complications between arthroplasty and osteosynthetic fixation (DHS or PFN) for intertrochanteric fractures. A 1-year mortality was chosen as a main indicator as it depends on the surgical trauma as well as the rapid return to preinjury activity and further complications. A 1year period was chosen as the mortality risk approaches that of an age-matched reference population after this interval $[32,35]$.

\section{Patients and methods}

A total of 308 patients who were treated for trochanteric femoral fractures between 1992 and 2005 with a minimum age of 60 years were enrolled in this study. Seventeen patients with pathologic fractures due to metastases were excluded. Information about survival after 1 year could be achieved from 283 of the 291 patients.

Two hundred and seventeen patients $(76.7 \%)$ were female. The mean age at the time of surgery was 80.5 $( \pm 9)$ years ranging from 60 to 98 years. Women ( $82 \pm 8$ years) of our cohort were significantly older than men $(75.5 \pm 11$ years; $P<0.01)$.

The fracture type was classified according to the System of the Orthopedic Trauma Association (AO/OTA) [24]. Pertrochanteric two part fractures are classified as A1-type, multi-part fractures as A2-type and reversed oblique intertrochanteric fractures as A3-type fractures. While all A1type fractures are considered to be stable, most of the A2 and all A3 type fractures are unstable [19]. The distribution of the fracture types within the treatment groups is displayed in Fig. 1.

A total of 109 patients $(38.5 \%)$ were treated with a "dynamic hip screw" (DHS by Synthes ${ }^{\circledR}$ ). Within this group there were mainly stable fractures type A1 (52\%) or A2 (44\%; Table 1); 132 patients $(46.6 \%)$ were treated with primary arthroplasty, 117 with a total hip replacement (THR) and 15 with a bipolar hemiarthroplasty (HA). Since

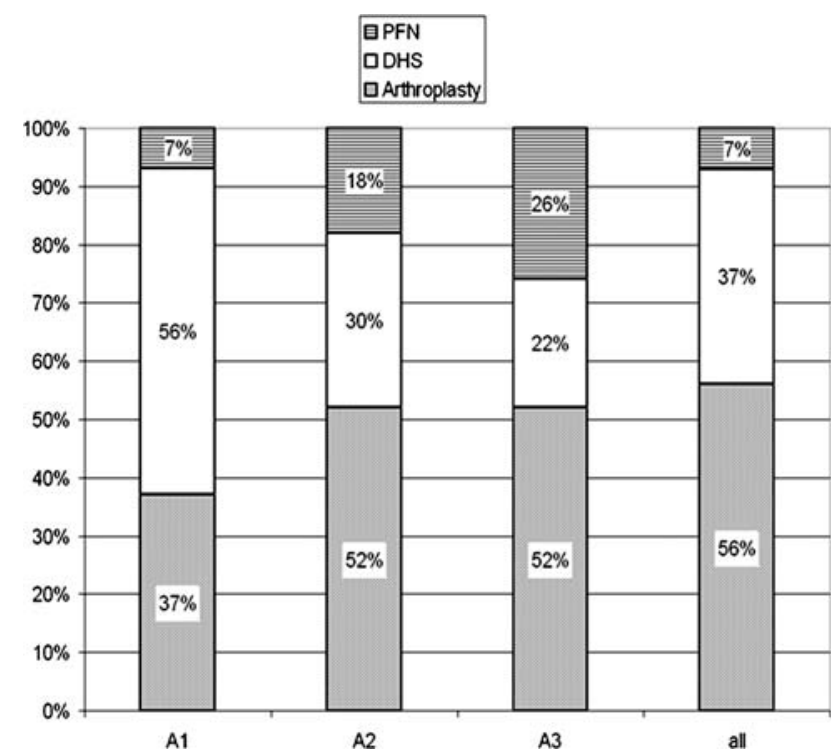

Fig. 1 Distribution of the surgical treatment depending on the fracture type. The dynamic hip screw (DHS) was mostly used in more stable fractures, while the proximal femoral nail (PFN) was mainly used in A3-type fractures $\left(X^{2}=22.4, P<0.001\right)$

2000 PFN (Synthes ${ }^{\circledR}$ ) was used in 42 of the 100 cases, mainly for unstable fractures in patients without advanced osteoarthritis. As demonstrated in Table 1, these patients were younger and more frequently male $(P<0.05)$.

Outcome variables

Primary outcome variable was the 1-year mortality risk (Table 2). Furthermore, the occurrence of complications which led to further interventions was analyzed in multiple regression analysis. These were dislocation of the hip, nonunion of the fracture, cutting out of the hip screw, infections, thrombosis and hematoma.The Merle d'Aubigne test

Table 1 Description of the baseline variables within the treatment groups

\begin{tabular}{llll}
\hline & Arthroplasty & DHS & PFN \\
\hline Age (years) & $83 \pm 7$ & $79 \pm 9$ & $75 \pm 12$ \\
$\begin{array}{l}\text { Number of patients } \\
\text { Gender }\end{array}$ & 132 & 109 & 42 \\
Female & $115(87 \%)$ & $80(73 \%)$ & $26(62 \%)$ \\
Male & $17(13 \%)$ & $29(27 \%)$ & $16(38 \%)$ \\
$\geq 4$ comorbidities & $63(48 \%)$ & $56(51 \%)$ & $17(41 \%)$ \\
Fracture type & & & \\
A1 & $37(28 \%)$ & $57(52 \%)$ & $7(17 \%)$ \\
A2 & $82(63 \%)$ & $48(44 \%)$ & $29(69 \%)$ \\
A3 & $12(9 \%)$ & $5(4 \%)$ & $6(14 \%)$ \\
Year of injury & & & \\
$1992-1999$ & $111(84 \%)$ & $72(66 \%)$ & $0(0 \%)$ \\
$2000-2005$ & $21(16 \%)$ & $37(34 \%)$ & $42(100 \%)$ \\
\hline
\end{tabular}


Table 2 The distribution of fracture type and treatment and its specific mortality
$T H R$ total hip replacement, $H A$ hemiarthroplasty, $P F N$ proximal femoral nail, $D H S$ dynamic hip screw

\begin{tabular}{|c|c|c|c|c|c|c|c|c|c|}
\hline & \multicolumn{3}{|c|}{ 1992-1999 } & \multicolumn{3}{|c|}{ 2000-2005 } & \multicolumn{3}{|c|}{ 1992-2005 } \\
\hline & $n$ & Death & $\begin{array}{l}\text { Mortality } \\
(\%)\end{array}$ & $n$ & Death & $\begin{array}{l}\text { Mortality } \\
(\%)\end{array}$ & $n$ & Death & $\begin{array}{l}\text { Mortality } \\
(\%)\end{array}$ \\
\hline A 1 & 71 & 19 & 26.8 & 29 & 4 & 13.8 & 100 & 23 & 23.0 \\
\hline THR & 34 & 9 & 26.5 & 0 & 0 & & 34 & 9 & 26.5 \\
\hline HA & 0 & 0 & & 3 & 1 & 33.3 & 3 & 1 & 33.3 \\
\hline DHS & 37 & 10 & 27.0 & 19 & 3 & 15.8 & 56 & 13 & 23.2 \\
\hline PFN & 0 & 0 & 0.0 & 7 & 0 & 0.0 & 7 & 0 & 0.0 \\
\hline $\mathrm{A} 2$ & 95 & 28 & 29.5 & 66 & 13 & 19.7 & 161 & 41 & 25.5 \\
\hline THR & 65 & 24 & 36.9 & 6 & 2 & 33.3 & 71 & 26 & 36.6 \\
\hline HA & 0 & 0 & & 12 & 1 & 8.3 & 12 & 1 & 8.3 \\
\hline DHS & 30 & 4 & 13.3 & 18 & 2 & 11.1 & 48 & 6 & 12.5 \\
\hline PFN & 0 & 0 & & 30 & 8 & 26.7 & 30 & 8 & 26.7 \\
\hline A 3 & 17 & 6 & 35.3 & 5 & 1 & 20.0 & 22 & 7 & 31.8 \\
\hline THR & 12 & 5 & 41.6 & 0 & 0 & & 12 & 5 & 41.6 \\
\hline HA & 0 & 0 & & 0 & 0 & & 0 & 0 & \\
\hline DHS & 5 & 1 & 20.0 & 0 & 0 & & 5 & 1 & 20.0 \\
\hline PFN & 0 & 0 & & 5 & 1 & 20.0 & 5 & 1 & 20.0 \\
\hline All fractures & 183 & 53 & 29.0 & 100 & 18 & 18.0 & 283 & 71 & 25.1 \\
\hline THR & 111 & 38 & 34.2 & 6 & 2 & 33.3 & 117 & 40 & 34.2 \\
\hline HA & 0 & 0 & & 15 & 2 & 13.3 & 15 & 2 & 13.3 \\
\hline DHS & 72 & 15 & 20.8 & 37 & 5 & 13.5 & 109 & 20 & 18.4 \\
\hline PFN & 0 & 0 & & 42 & 9 & 21.4 & 42 & 9 & 21.4 \\
\hline
\end{tabular}

(0 to 18 points) was used to assess the patients [10]. We further questioned whether the patients returned to their preoperative status (e.g. living at home).

\section{Surgical technique}

The proximal femoral nail (PFN by Synthes ${ }^{\circledR}$-Switzerland) or the dynamic hip screw (DHS by Synthes ${ }^{\circledR}$-Switzerland) was used according to the manufacturer's instructions. For closed reduction the patients were positioned supine on a fracture table. Only $135^{\circ}$ four hole-DHS plates without additional trochanteric stabilizing plates or tension band wires were used in this series.

For hemiarthroplasty a standard cemented stem (Weller, Aesculap, Germany) and a bipolar head (DePuy, Leeds, England) were used. All femoral stems were cemented using the modern 3D generation cementing technique [2]. In cases of total hip replacement, a polyethylene cup (Aesculap ${ }^{\circledR}$, Germany) was cemented in the same manner (Fig. 3).

\section{Statistics}

First we performed univariate analysis of independent variables (age, sex, treatment, preoperative risk factors, etc.) and mortality using Fischer's exact test for qualitative variables and ANOVA for quantitative variables. The homogeneity of variance was checked by Levene test. All tests were two-sided and a $P \leq 0.05$ was considered to be significant.

The influence of treatment on mortality was checked by a multiple logistic regression model adjusted for the presence of preoperative comorbidities (four or more vs. up to three), fracture classification, age, gender, complications requiring revision surgery and year of surgery.

We used RR additional to OR because the more frequent the outcomes becomes, the more the odds ratio will overestimate the risk ratio when it is more than 1 or underestimate the risk ratio when it is less than 1 [34]. Odds ratios (OR) were transferred to relative risks (RR) according to the method of Zhang et al. [34] with the formula: $\mathrm{RR}=\mathrm{OR} /$ $\left[\left(1-P_{0}\right)+\left(P_{0} \times \mathrm{OR}\right)\right]$, where $P_{0}$ is the incidence of the outcome in the nonexposed group (reference category), and OR the odds ratio given by the multiple analysis. A RR $<1$ refers to a factor category that is mitigating (decreasing) the risk of the outcome (e.g. dying) when present, an RR $>1$ refers to a factor category that is increasing that risk when present compared with the reference category.

All analyses were conducted with the SPSS statistic software for Windows 12.0 (SPSS, Chicago, IL, USA). 


\section{Results}

\section{Surgery}

Eighty-five percent of our patients were operated within 1 day after admission. In the other cases, operation was delayed to improve the preoperative condition of the patient, e.g. by transfusion or change of medication. This was independent of the treatment groups $(P=0.307)$. Mean blood loss and operating time differed significantly depending on the type of operation. The mean blood loss for arthroplasty $(1,050 \pm 700 \mathrm{ml})$ was significantly higher than for fixation with a DHS $(409 \pm 360 \mathrm{ml})$ or PFN $(332 \pm 277 \mathrm{ml} ; P<0.001)$. Implantation of a hip replacement took a mean of $115 \pm 36 \mathrm{~min}$, that of a DHS $73 \pm 38 \mathrm{~min}$ and of a PFN $84 \pm 32 \mathrm{~min} \quad(P<0.001)$ including time for closed reduction on the extension rag. Fracture classification significantly influenced operating time if an arthroplasty was performed. It was $100 \pm 24 \mathrm{~min}$ for A.1, $121 \pm 39 \mathrm{~min}$ for A.2 and $127 \pm 26 \mathrm{~min}$ for A.3-fractures $(P=0.012)$. The blood loss was similarly influenced $(800 \pm 460 \mathrm{ml}$ for A.1, $1,200 \pm 800 \mathrm{ml}$ for A.2, $900 \pm 500 \mathrm{ml}$ for A. 3 fractures; $P=0.019)$

\section{Mortality}

Six patients $(2.1 \%)$ died during hospitalization, 25 (8.9\%) within 90 days. These were patients with considerable preoperative risk factors; 71 patients $(25.2 \%)$ died within 1 year (Table 2).

\section{Influence of gender and age}

As demonstrated in Fig. 2, survival was correlated to age and gender; $34.8 \%$ of the male and $24.9 \%$ of our female patients dies within the first year (relative risk 0.34, $P=0.004$; Table 4). Not considering the different treatment groups patients over the age of 80 years had an increased mortality risk $(P=0.004)$.

\section{Influence of comorbidities}

The comorbidities and their prevalence are shown in Table 3. Of the single comorbidities only cardiac arrhythmia and cerebral diseases $(P=0.04)$ showed a significant influence on mortality. Logistic regression analysis demonstrated that four or more comorbidities increased the risk to die by $78 \%$ (relative risk $1.78, P=0.009$; Table 4). Forty-eight percent of our patients had four or more comorbidities and showed a mortality risk of $33.3 \%$ compared with $17.4 \%$ if they had less than four $(P=0.032$ in $\chi^{2}$-test).

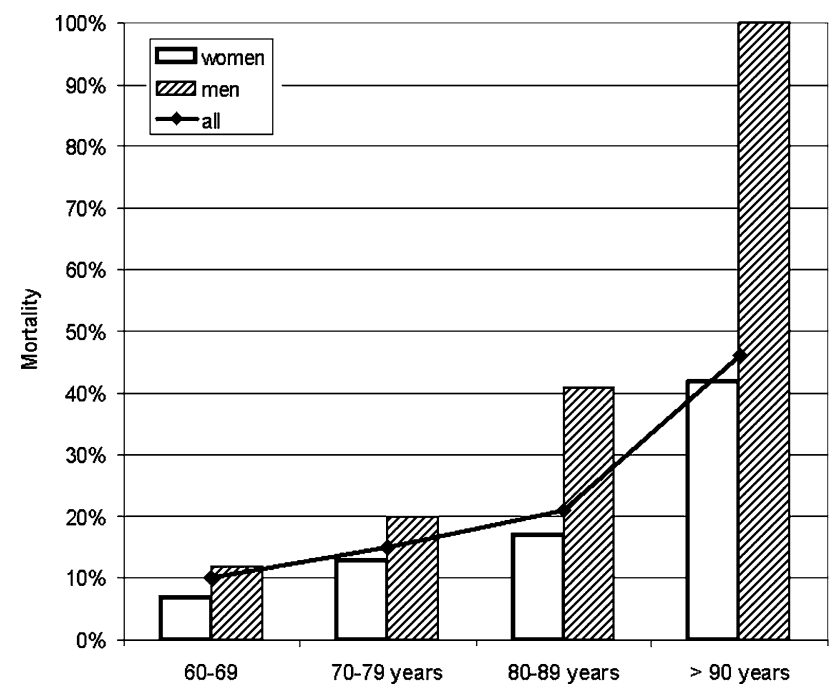

Fig. 2 Influence of age and gender. Independent of the treatment and fracture type the mortality risk was significantly influenced by age for both genders ( $P=0.018$ for men, $P=0.002$ for women). After multivariate analysis, the risk to die was significantly lower for woman (relative risk $0.34, P=0.004$ ) and higher for patients over the age of 90 years (relative risk $3.61 ; P=0.009$ )

Influence of fracture-classification and treatment

Only pertrochanteric fractures were enrolled in this study and sorted according to the AO/OTA classification (Fig. 1). While the mortality did not differ between A1- (23.0\%) and A2-type fractures (25.5\%), it was higher in A3-type fractures (31.8\%; Table 2). As this fracture type affected only $7 \%$ of our patients, it did not significantly influence the mortality risk $(P=0.42)$.

About $18.4 \%$ of the patients who received a dynamic hip screw, $21.4 \%$ of those who received a proximal femoral nail and 33\% in the arthroplasty groups (THR and HA) died within 1 year $(P=0.011)$. As the indication for surgery was not randomized but decided on fracture classification and clinical status we attempted to reduce these influences in a multiple logistic regression analysis (Table 4). All potential influencing factors as gender, age, fracture type and amount of comorbidities were taken into account. If categorical variables were used to evaluate the interaction between fracture classification and treatment, we could not find a statistical influence of surgical treatment on mortality (Table 4). The relative risk to die was decreased for A.1and A.2-type fractures, treated with a DHS, but this did not reach significance levels. As only seven patients with a A.1-type fracture were treated with a PFN (and all of them survived), no sensible statistical analysis can be done for this category. As all devices showed good results for this kind of fracture, the decision should be based on other parameters for A.1-type fractures. 
Table 3 The prevalence and relative risks of the most common comorbidities

\begin{tabular}{|c|c|c|c|c|c|c|c|}
\hline Comorbidity & $n$ & Po & $P$ (Fisher's exact) & $\mathrm{RR}$ & OR & CI $95 \%$ & $P$ (log. reg.) \\
\hline Heart attack & 124 & 0.340 & 0.43 & 1.12 & 1.19 & $0.56-2.14$ & 0.69 \\
\hline Cardiac arrhythmia & 47 & 0.354 & $0.01 * *$ & 1.10 & 1.16 & $1.02-2.43$ & $0.04 *$ \\
\hline Cardiac insufficiency & 111 & 0.304 & 0.82 & 1.44 & 1.79 & $0.67-3.18$ & 0.55 \\
\hline Hypertonus & 154 & 0.268 & 1.00 & 0.98 & 0.97 & $0.55-1.73$ & 0.92 \\
\hline Pulmonary diseases & 66 & 0.288 & 0.73 & 1.07 & 1.1 & $0.57-2.16$ & 0.77 \\
\hline Anemia & 47 & 0.319 & 0.35 & 1.26 & 1.43 & $0.69-2.96$ & 0.33 \\
\hline Renal insufficiency & 47 & 0.261 & 1.00 & 0.85 & 0.81 & $0.38-1.75$ & 0.60 \\
\hline Cerebral diseases & 127 & 0.336 & 0.30 & 1.42 & 1.81 & $1.02-3.22$ & $0.04 *$ \\
\hline Diabetes mellitus & 92 & 0.326 & 0.28 & 1.24 & 1.41 & $0.79-2.52$ & 0.25 \\
\hline Metabolic diseases & 30 & 0.233 & 0.82 & 0.75 & 0.7 & $0.27-1.80$ & 0.46 \\
\hline Alcohol/nicotine/other drugs & 29 & 0.321 & 0.35 & 1.51 & 1.98 & $0.79-4.99$ & 0.14 \\
\hline Gastrointestinal disease & 42 & 0.244 & 0.31 & 0.76 & 0.71 & $0.32-1.64$ & 0.43 \\
\hline Others & 57 & 0.304 & 0.85 & 1.01 & 1.01 & $0.51-2.03$ & 0.96 \\
\hline
\end{tabular}

Relative risks (RR) are computed from odds ratios (OR) by the following formula: RR $=\mathrm{OR} /\left[\left(1-P_{0}\right)+\left(P_{0} \times \mathrm{OR}\right)\right]$

$P_{0}$ is the proportion of patients with the respective disease dying within 1-year after proximal femoral fracture

$\mathrm{RR}<1.0$ represents a minor risk of mortality; $\mathrm{RR}>1.0$ represents a major risk of mortality compared with patients without this criteria; $* P \leq 0.05 ; * * P \leq 0.01$

Because our treatment regime was changed in the beginning of 2000 (introduction of the PFN, new bipolar hemiarthroplasty instead of total hip arthroplasty; Table 2), we implicated the time of surgery in our analysis. Since then the 1-year mortality after arthroplasty decreased from 34.2 to $19 \%$ ( $P=0.26$, Fisher's exact test). Although over all mortality decreased from 29 to $18 \%$, no influence of time of surgery on the mortality risk could be found using multivariate regression analysis $(P=0.54$; Table 4$)$.

\section{Influence of complications}

The only postoperative complication which influenced the survival rate was postoperative pneumonia. It occurred in 13 cases independent of the treatment groups $(P=0.26)$. Six of the patients died within 1 year $(P=0.048)$.

The DHS had a revision rate of $8.1 \%$, while the PFN needed reoperations in nine cases $(22.5 \%)$. The main reason was cutting out of the screw in the osteoporotic bone and postoperative hematoma. Due to cutting out and fixation failure secondary hip arthroplasty was performed after failed internal fixation ten times. It happened six times (5.4\%) after a DHS and four times $(9.8 \%)$ after a PFN.

The main complication after arthroplasty was dislocation, which occurred in 16 patients (12\%). It did not occur with bipolar hemiarthroplasty. While dislocation was only a minor problem in A1-type fractures (7\%), it occurred in ten A2-type (12\%) and two of the nine A3-type fractures $(22 \%)$. Patients were usually treated by closed reduction and physiotherapy and it did not influence mortality $(P=0.78)$.

\section{Rehabilitation}

The mean hospital stay was 18 days and did not differ significantly between the three treatment groups $(P=0.7)$. It prolonged to a mean of 30 days if a reoperation became necessary $(P=0.003)$. Patients who were ambulatory before the injury could walk with a walker or sticks at time of discharge; $80 \%$ of the surviving patients who were independent before the injury regained their preoperative status after 1 year. Since the year 2000 patients were encountered to a prospective registry. The mean Merle d'Aubigné score (0-18 points) for the surviving 78 patients was $13.8 \pm 2.5$. No significant differences could be found between the three treatment groups $(P=0.122)$.

\section{Discussion}

While primary arthroplasty is a standard procedure for femoral neck fractures, little experience exists for trochanteric fractures $[4,5,9,28]$. They were primarily used as a salvage procedure after failed internal fixation $[12,15,21,23$, 31]. Most authors implanted special calcar replacement devices, which are expensive and require the removal of large portions of the proximal femur [3, 8, 13, 28]. We used a standard cemented stem and either a standard cemented cup or a bipolar head since the 1970s in our hospital. As it proved superior to former methods of internal fixation even for pertrochanteric fractures it was the treatment of choice since 1992 [26]. From the year 2000 on hemiarthroplasty was routinely used instead of total hip arthroplasty and the 
Table 4 Multiple logistic regressions analysis of a 1-year mortality after proximal femoral fractures of elderly patients

Relative risks (RR) are computed from OR (odds ratio) by the following formula:

$\mathrm{RR}=\mathrm{OR} /\left[\left(1-P_{0}\right)+\right.$

$\left.\left(P_{0} \times \mathrm{OR}\right)\right]$

$P_{0}$ is the proportion of patients in the respective reference category dying within 1-year after proximal femoral fracture

$\mathrm{RR}<1.0$ represents a minor risk of mortality; RR > 1.0 represents a major risk of mortality compared with patients without this criteria

Number of cases in all models: 282

${ }^{a}$ Reference: TEP

b Reference: A1

${ }^{c}$ Reference: $<70$ years

${ }^{\mathrm{d}}$ Reference: male gender

e Reference: A1*TEP

\begin{tabular}{|c|c|c|c|c|}
\hline \multirow[t]{2}{*}{$\begin{array}{l}\text { Description } \\
\text { of the analysis }\end{array}$} & \multicolumn{4}{|c|}{$\begin{array}{l}\text { Influence of interaction of kind of treatment and fracture classification after } \\
\text { adjusting age, gender, comorbidities, revision surgery and date of surgery }\end{array}$} \\
\hline & Odds ratio & $95 \% \mathrm{CI}$ & $P$ & Relative risk \\
\hline \multicolumn{5}{|c|}{ Influence: interaction of kind of treatment and fracture classification ${ }^{\mathrm{e}}$} \\
\hline A $1 *$ PFN & 0.000 & 0.000 & 0.999 & 0.00 \\
\hline A $1 *$ DHS & 0.638 & $0.228-1.787$ & 0.392 & 0.71 \\
\hline $\mathrm{A} 2 * \mathrm{TEP}$ & 1.391 & $0.566-3.420$ & 0.472 & 1.25 \\
\hline $\mathrm{A} 2 * \mathrm{PFN}$ & 1.124 & $0.272-4.647$ & 0.872 & 1.08 \\
\hline A $2 *$ DHS & 0.372 & $0.112-1.237$ & 0.107 & 0.46 \\
\hline A $3 *$ TEP & 2.120 & $0.502-8.954$ & 0.307 & 1.59 \\
\hline A $3 *$ PFN & 1.017 & $0.087-11.833$ & 0.989 & 1.01 \\
\hline A $3 *$ DHS & 1.093 & $0.096-12.387$ & 0.943 & 1.06 \\
\hline \multicolumn{5}{|c|}{ Influence: age category ${ }^{\mathrm{c}}$} \\
\hline $70-79$ years & 1.231 & $0.334-4.532$ & 0.755 & 1.19 \\
\hline $80-89$ years & 2.798 & $0.785-9.970$ & 0.112 & 2.23 \\
\hline$>90$ years & 6.381 & $1.603-25.403$ & 0.009 & 3.61 \\
\hline \multicolumn{5}{|l|}{ Influence: gender ${ }^{\mathrm{d}}$} \\
\hline Female gender & 0.338 & $0.161-0.708$ & 0.004 & 0.44 \\
\hline \multicolumn{5}{|c|}{ Influence: comorbidities complications and year of surgery } \\
\hline$\geq 4$ comorbidities & 2.238 & $1.219-4.109$ & 0.009 & 1.78 \\
\hline Revision surgery & 1.195 & $0.448-3.184$ & 0.722 & 1.13 \\
\hline Surgery after 2000 & 0.775 & $0.343-1.752$ & 0.541 & 0.83 \\
\hline
\end{tabular}

proximal femoral nail was introduced for patients without advanced osteoarthritis.

The ideal treatment for intertrochanteric fractures is still under debate as none of the existing osteosynthetic devices could prove its superiority in former studies [16, 25, 29, 30]. The most frequent problem in elderly patients who usually are not able to walk without weight bearing was a cutting out of the hip screw which occurred in 4 to $20 \%$ of the reported cases $[4,6]$. In our series this complication was only seen in comminuted fractures (A2 and A3 type). Thus, 10 times $(6.2 \%$ of the internal fixation devices) a secondary hemiarthroplasty was performed. Immediate full weight bearing regardless of bone quality is an advantage of primary cemented arthroplasty. In our hospital, all patients are encouraged to stand up the day after surgery. Dislocation was the major complication in patients treated with a total hip replacement after comminuted pertrochanteric fractures. This high dislocation rate is rarely seen after primary hip arthroplasty but well known even for femoral neck fractures [22] or revision surgery [33] and can be attributed to insufficient muscular stability. Fractures of the greater or lesser trochanter might exaggerate this problem. The use of bipolar arthroplasty instead of total hip replacements can reduce this complication to an acceptable rate [11, 28]. Since we use total hip arthroplasty only in patients of good physical shape with severe osteoarthritis we did not see any dislocations.
Ambulatory levels and clinical scores are considerable affected by the preoperative status. Since clinical examination usually cannot be obtained for all patients, reliable comparison is difficult. Some authors use telephone interviews [4] or report about less than $50 \%$ of their patients for a 1-year follow-up [10]. In both cases it can be assumed that patients with bad functional results are not regularly included. We could also examine only $78 \%$ of the last 100 patients clinically and therefore do not want to overemphasize these findings. Instead we chose the 1-year mortality risk as the primary outcome parameter as it could be obtained for all patients and is related to the postoperative ambulatory status as well as to the operative trauma [14]. In a previous study with more than 500 fractures, we could demonstrate that patients who regained their independency and were able to attend a rehabilitation institution had a significantly lower mortality risk [7], which was further supported in this study.

Mortality was significantly influenced by patient related factors such as gender, age and comorbidities but not by the fracture type. In accordance with our former studies and other authors [7, 17, 20, 26] few single comorbidity influenced the mortality risk whereas the sum of four or more comorbidities increased the risk to die by approximately $78 \%$ (Tables 3 and 4). Patients who received a PFN or DHS were significantly younger and healthier than those in the arthroplasty group. These influences were reduced by 
A

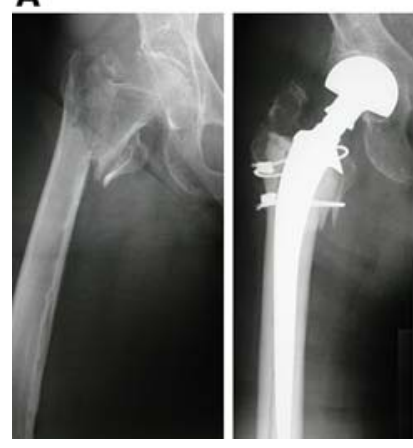

Fig. 3 Examples of treatment of A2-type fractures with a hemiendoprosthesis and tension band wires. Depending on the fracture type different ways of fixating the trochanteric region with wires were used. In the case of a calcar fragment reaching distal to the lesser trochanter

multivariate regression analysis (Table 4). Furthermore, the interaction of fracture type and treatment was taken into account. Considering these influences, no significant influence of one of the three treatment groups on the mortality risk could be found. In studies that only use internal fixation devices mortality risks comparable with our over all mortality were found [27], thus - in accordance with other authors [3, 13]—we think that cemented hemiarthroplasty is an alternative to internal fixation in elder patients especially as our revision rate was significantly lower for arthroplasty compared with internal fixation.

Only Chan et al. [4] published a study about the use of a standard hemiarthoplasty for the treatment of displaced intertrochanteric fractures. In their small group of 54 patients they found a mortality rate of $31.5 \%$ within 1 year which did not differ from comparable age-matched studies. The walking ability of their patients was favorable compared with other studies with internal fixation. We agree that immediate full weight bearing, which can be achieved after cemented arthroplasty, is crucial for these patients.

Haentjens et al. compared 37 patients who received a calcar replacement device with 42 patients of a retrospective group, who were treated by internal fixation and found an advantage in functional outcome [10]. Although the mortality rate could not be decreased, early walking with full weight bearing reduced the incidence of pressure sores, pulmonary infection and atelectasis. Kim et al. [18] who compared a calcar replacement prosthesis with intramedullary fixation in a prospective study in two small groups of 29 patients could not find a significant difference concerning the functional outcomes, but the cut-out rate of the hip screw was $7 \%$ in their patients.

Up to now a clear indication of arthroplasty in the treatment of pertrochanteric fractures does not exist. Although operation time and blood loss are higher no significant difference concerning the mortality rate between primary arthroplasty and internal fixation could be found, but the

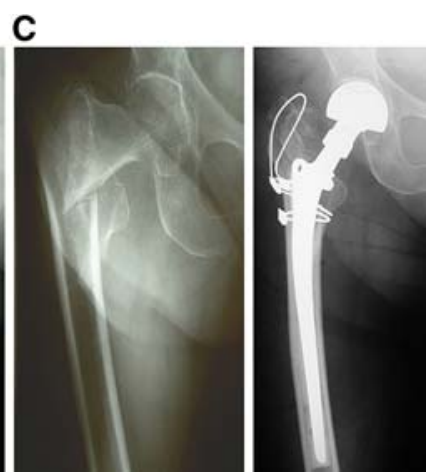

a temporary reduction with a cerclage wire or reduction bone clamp was used before reaming. Final fixation of the greater trochanter was performed after reduction of the hip with cerclages or a tension band

revision rate in the arthroplasty group was significantly smaller especially since we use bipolar hemiarthroplasty instead of a total hip replacement. If the cemented arthroplasty has been performed accurately, there is very little concern about weight bearing. Furthermore, primary arthroplasty eliminates the possibility for malunion, cut-out of the hip screw and avascular necrosis of the femoral head. But primary arthroplasty is a technically challenging procedure. All lose fragments including the greater and the lesser trochanter have to be attached with cerclage wires before cementing the stem to prevent extrusion (Fig. 3) and especially in utterly comminuted fractures orientation of the rotation and leg length can be demanding.

The DHS is not suitable for reverse oblique and comminuted fractures $[19,30]$ but for stable fractures it seems to be advantageous to short femoral nails regarding reoperation rate and fracture fixation failure in the literature $[16,29]$. We further support the recommendation that the DHS should be used for stable A1- and A2.1-type fractures while an intramedullary device is advantageous for unstable fractures. Primary cemented arthroplasty is a viable option for the treatment of trochanteric fractures in a selected group of previously independent mobile patients especially if osteoporosis would prevent full weight bearing or osteoarthritis would make further operations necessary. The routine use of total hip arthroplasty was abandoned in our hospital as the luxation rate was higher than after hemiarthroplasty. It is still used as salvage procedure after failed internal fixation in elder patients with bad bone quality.

\section{References}

1. Blomfeldt R, Tornkvist H, Ponzer S, Soderqvist A, Tidermark J (2005) Comparison of internal fixation with total hip replacement for displaced femoral neck fractures. Randomized, controlled trial performed at four years. J Bone Joint Surg Am 87:1680-1688 
2. Breusch SJ, Schneider U, Kreutzer J, Ewerbeck V, Lukoschek M (2000) Effects of the cementing technique on cementing results concerning the coxal end of the femur. Orthopäde 29:260-270

3. Broos PL, Willemsen PJ, Rommens PM, Stappaerts KH, Gruwez JA (1989) Pertrochanteric fractures in elderly patients: treatment with a long-stem/long-neck endoprosthesis. Unfallchirurg 92:234-239

4. Chan KC, Gill GS (2000) Cemented hemiarthroplasties for elderly patients with intertrochanteric fractures. Clin Orthop Relat Res 371:206-215

5. Dobbs RE, Parvizi J, Lewallen DG (2005) Perioperative morbidity and 30-day mortality after intertrochanteric hip fractures treated by internal fixation or arthroplasty. J Arthroplasty 20:963-966

6. Fogagnolo F, Kfuri M Jr, Paccola CA (2004) Intramedullary fixation of pertrochanteric hip fractures with the short AO-ASIF proximal femoral nail. Arch Orthop Trauma Surg 124:31-37

7. Geiger F, Schreiner K, Schneider S, Pauschert R, Thomsen M (2006) Proximal fracture of the femur in elderly patients: the influence of surgical care and patient characteristics on post-operative mortality. Orthopade 35:651-658

8. Green S, Moore T, Proano F (1987) Bipolar prosthetic replacement for the management of unstable intertrochanteric hip fractures in the elderly. Clin Orthop Relat Res 224:169-177

9. Grimsrud C, Monzon RJ, Richman J, Ries MD (2005) Cemented hip arthroplasty with a novel cerclage cable technique for unstable intertrochanteric hip fractures. J Arthroplasty 20:337-343

10. Haentjens P, Casteleyn PP, De BH, Handelberg F, Opdecam P (1989) Treatment of unstable intertrochanteric and subtrochanteric fractures in elderly patients: primary bipolar arthroplasty compared with internal fixation. J Bone Joint Surg Am 71:1214-1225

11. Haentjens P, Casteleyn PP, Opdecam P (1994) Primary bipolar arthroplasty or total hip arthroplasty for the treatment of unstable intertrochanteric and subtrochanteric fractures in elderly patients. Acta Orthop Belg 60(suppl 1):124-128

12. Haidukewych GJ, Berry DJ (2003) Hip arthroplasty for salvage of failed treatment of intertrochanteric hip fractures. J Bone Joint Surg Am 85-A:899-904

13. Harwin SF, Stern RE, Kulick RG (1990) Primary Bateman-Leinbach bipolar prosthetic replacement of the hip in the treatment of unstable intertrochanteric fractures in the elderly. Orthopedics 13:1131-1136

14. Imura K, Ishii Y, Yagisawa K, Matsueda M (2000) Postoperative ambulatory level after hip fracture in the elderly predicts survival rate. Arch Orthop Trauma Surg 120:369-371

15. Jacofsky DJ, Haidukewych GJ, Zhang H, Sim FH (2004) Complications and results of arthroplasty for salvage of failed treatment of malignant pathologic fractures of the hip. Clin Orthop Relat Res 427:52-56

16. Jones HW, Johnston P, Parker M (2006) Are short femoral nails superior to the sliding hip screw? A meta-analysis of 24 studies involving 3,279 fractures. Int Orthop 30:69-78

17. Kenzora JE, McCarthy RE, Lowell JD, Sledge CB (1984) Hip fracture mortality. Relation to age, treatment, preoperative illness, time of surgery, and complications. Clin Orthop Relat Res 186:4556

18. Kim SY, Kim YG, Hwang JK (2005) Cementless calcar-replacement hemiarthroplasty compared with intramedullary fixation of unstable intertrochanteric fractures: a prospective, randomized study. J Bone Joint Surg Am 87:2186-2192

19. Lorich DG, Geller DS, Nielson JH (2004) Osteoporotic pertrochanteric hip fractures: management and current controversies. Instr Course Lect 53:441-454

20. Lu-Yao GL, Baron JA, Barrett JA, Fisher ES (1994) Treatment and survival among elderly Americans with hip fractures: a population-based study. Am J Public Health 84:1287-1291

21. Lyman JR, Kelley SS, Lachiewicz PF (2004) Hip arthroplasty after extracapsular hip fracture: a matched pair cohort analysis. J Surg Orthop Adv 13:38-41

22. Mabry TM, Prpa B, Haidukewych GJ, Harmsen WS, Berry DJ (2004) Long-term results of total hip arthroplasty for femoral neck fracture nonunion. J Bone Joint Surg Am 86-A:2263-2267

23. Mehlhoff T, Landon GC, Tullos HS (1991) Total hip arthroplasty following failed internal fixation of hip fractures. Clin Orthop Relat Res 269:32-37

24. Muller ME, Nazarian S, Koch P, Schatzker J (1990) The comprehensive classification of fractures of long bones. Springer, Berlin, pp 120-121

25. Nuber S, Schonweiss T, Ruter A (2003) Stabilisation of unstable trochanteric femoral fractures. Dynamic hip screw (DHS) with trochanteric stabilisation plate vs. proximal femur nail (PFN). Unfallchirurg 106:39-47

26. Pauschert R, Niethard FU, Schöning B, Lurz G (1996) Letalität nach Frakturen des coxalen Femurendes im fortgeschrittenen Alter. Dt Ärzteblatt 93:102-107

27. Raunest J, Engelmann R, Jonas M, Derra E (2001) Morbidity and mortality in para-articular femoral fractures in advanced age: results of a prospective study. Unfallchirurg 104:325-332

28. Rodop O, Kiral A, Kaplan H, Akmaz I (2002) Primary bipolar hemiprosthesis for unstable intertrochanteric fractures. Int Orthop $26: 233-237$

29. Saudan M, Lubbeke A, Sadowski C, Riand N, Stern R, Hoffmeyer $P$ (2002) Pertrochanteric fractures: is there an advantage to an intramedullary nail?: a randomized, prospective study of 206 patients comparing the dynamic hip screw and proximal femoral nail. J Orthop Trauma 16:386-393

30. Utrilla AL, Reig JS, Munoz FM, Tufanisco CB (2005) Trochanteric gamma nail and compression hip screw for trochanteric fractures: a randomized, prospective, comparative study in 210 elderly patients with a new design of the gamma nail. J Orthop Trauma 19:229-233

31. Waddell JP, Morton J, Schemitsch EH (2004) The role of total hip replacement in intertrochanteric fractures of the femur. Clin Orthop Relat Res 429:49-53

32. White BL, Fisher WD, Laurin CA (1987) Rate of mortality for elderly patients after fracture of the hip in the 1980's. J Bone Joint Surg Am 69:1335-1340

33. Zhang B, Chiu KY, Wang M (2004) Hip arthroplasty for failed internal fixation of intertrochanteric fractures. J Arthroplasty 19:329-333

34. Zhang J, Yu KF (1998) What's the relative risk? A method of correcting the odds ratio in cohort studies of common outcomes. JAMA 280:1690-1691

35. Zuckerman JD (1996) Current concepts, hip fractures. N Engl J Med 334:1519-1525 